\title{
Efeito da interação idade da matriz x peso do ovo sobre o desempenho de codornas de corte
}

[Effect of female breeder age x egg weight interaction on the performance of meat type quails]

\author{
A.B. Corrêa $a^{1}$, M.A. Silva ${ }^{2,5}$, G.S.S. Corrêa ${ }^{3}$, G.G. Santos ${ }^{1}$, V.P.S. Felipe ${ }^{1}$, R.R. Wenceslau ${ }^{1}$, \\ G.H. Souza ${ }^{1,5}$, N.C.F.L. Campos ${ }^{4}$ \\ ${ }^{1}$ Aluno de pós-graduação - EV-UFMG - Belo Horizonte, MG \\ ${ }^{2}$ Escola de Veterinária - UFMG - Belo Horizonte, MG \\ ${ }^{3}$ Departamento de Ciências Básicas e Produção Animal - FAMEV-UFMT - Cuiabá, MT \\ ${ }^{4}$ Aluno de graduação - EV-UFMG - Belo Horizonte, MG \\ ${ }^{5}$ Bolsista do CNPq \\ RESUMO
}

\begin{abstract}
Avaliou-se a interação idade da matriz versus peso do ovo sobre o desempenho produtivo de codornas de corte (Coturnix coturnix coturnix) no $21^{\circ}$ e $42^{\circ}$ dias de idade. Em cada classe de idade da matriz, iniciada a partir de 70, 205 e 280 dias, foram incubados 600 ovos, separados em três categorias de peso: categoria 1 - ovos com 11,0-12,9g; categoria 2 - ovos com 13,0-14,9g e categoria 3 - ovos com 15,0-16,9g. Após a eclosão, em cada idade da matriz, foram utilizadas 225 codornas de um dia, de ambos os sexos, provenientes das três categorias de peso, sendo 75 codornas por categoria. O delineamento experimental foi inteiramente ao acaso, e os tratamentos consistiram das três classes de idades da matriz $\mathrm{x}$ três categorias de peso do ovo, com cinco repetições de 15 codornas. A dieta experimental foi única para todos os tratamentos com $28 \%$ proteína bruta e $2900 \mathrm{kcal}$ de energia metabolizável. A categoria peso do ovo e a classe de idade da matriz influenciaram o peso corporal, o ganho de peso e o consumo da dieta no $21^{\circ}$ e $42^{\circ}$ dias de idade. Codornas oriundas de ovos mais pesados e de matrizes das classes de 205 e 280 dias de idade apresentaram melhor desempenho $(\mathrm{P}<0,05)$. A viabilidade foi influenciada pela categoria peso do ovo, ou seja, codornas provenientes de ovos mais leves apresentaram menor viabilidade aos $21^{\circ}$ e $42^{\circ}$ dias de idade $(\mathrm{P}<0,05)$. Ovos mais pesados originaram codornas mais pesadas ao nascimento $(\mathrm{P}<0,05)$.
\end{abstract}

Palavras-chave: codorna de corte, idade da matriz, peso corporal, peso do ovo

\begin{abstract}
The effect of female breeder age $x$ egg weight interaction was evaluated on the performance of meat type quails (Coturnix coturnix coturnix) at $21^{\text {st }}$ and $42^{\text {nd }}$ days of age. For every female breeder age class (70, 205, and 280 days of age), 600 eggs were classified according to egg weight class (class 1: 11.0-12.9; class 2: 13.0-14.9, and class 3: 15.0-16.9g). A total of 225 quails of both genders, totaling 75 quails for every egg weight class were used in this study. A completely randomized experimental design with five replicates of 15 quails was used. The experimental diets were formulated to contain $28 \%$ crude protein and 2,900 kcal of metabolizable energy (ME). Weight gain, body weight, feed consumption, and weight gain: feed consumption ratio from hatch to $21^{\text {st }}$ day and from hatch to $42^{\text {nd }}$ day of age were recorded. Both egg weight and female breeder age classes affected body weight, weight gain, and feed consumption at $21^{\text {st }}$ and $42^{\text {nd }}$ days of age. Quails from heavier egg weight class and female breeder age classes 205 and 280 days of age showed higher performance $(P<0.05)$. Quail viability was affected by egg weight class, i.e. quails from lighter eggs showed lower viability at $21^{\text {st }}$ and $42^{\text {nd }}$ days of life. Heavier eggs originated heavier quails at hatch $(P<0.05)$
\end{abstract}

Keywords: meat type quail, female breeder age, body weight, egg weight

Recebido em 16 de agosto de 2009

Aceito em 21 de fevereiro de 2011

E-mail: andrecorreaufpa@hotmail.com

Apoio: FAPEMIG 


\section{Corrêa et al.}

\section{INTRODUÇÃo}

Dentre os diversos fatores que podem influir no desempenho do lote (genética, nutrição, sanidade, ambiente de criação, manejo), a idade da matriz e o peso do ovo à incubação se destacam. A idade da matriz tem influência direta sobre a qualidade, composição e tamanho do ovo, pois, com o avanço da idade da matriz, ocorre redução na taxa de postura, alteração nos constituintes do ovo, principalmente gema e albúmen, e aumento no tamanho dos ovos (Reis et al., 1997; Rocha et al., 2008).

O peso do ovo influencia o peso do pinto ao nascimento, que, por sua vez, influencia o desempenho ao abate. Isso ocorre em razão das associações existentes entre peso do ovo e peso do pinto, e do peso do pinto e peso ao abate (Wilson, 1991). A prática rotineira adotada no incubatório - classificar ovos pelo peso e idade da matriz para gerar lotes e pintos de corte mais homogêneos e facilitar o manejo durante o período de criação, a regulagem de equipamentos no galpão e o abate - é decorrente da correlação positiva entre o peso do ovo e o peso do pinto.

Outro aspecto importante é que o crescimento do embrião é dependente, basicamente, do albúmen e da gema do ovo, que são os principais fornecedores de nutrientes para 0 desenvolvimento do embrião. Nas primeiras 24 horas após o nascimento, o saco vitelino representa a principal reserva de nutrientes do pintainho, por se constituir de porções remanescentes da utilização da gema e albúmen pelo embrião, que será importante no desenvolvimento inicial do pinto (Vieira e Moran Jr., 1999).

Ovos maiores provenientes de matrizes mais velhas normalmente apresentam maior peso da gema e, por consequência, maiores saco vitelino e quantidades de nutrientes para o pinto ao nascimento (Noble et al., 1986; Ding e Lilburn, 1996; Rocha et al., 2008). Os resultados obtidos por Peebles et al. (1999) indicam que matrizes mais velhas apresentam melhores rendimentos de carcaça e de peito no $42^{\circ}$ dia de idade. Da mesma forma, Maiorka et al. (2003) observaram que frangos provenientes de matrizes mais velhas apresentaram maiores consumo da dieta e ganho de peso no $42^{\circ}$ dia de idade.
Ao classificarem os pintos de frangos de corte em leves, médios e pesados durante o alojamento das aves, Lara et al. (2005) encontraram maior peso ao abate e melhor rendimento de carcaça em frangos que apresentavam maior peso ao nascimento. Lotes de frangos oriundos de pintos mais pesados apresentam mortalidade mais baixa, e isso pode influenciar a rentabilidade da criação (Leandro et al., 2006).

Em codornas de corte, a seleção dos ovos para incubação geralmente é subjetiva, e os pesos dos ovos incubados variam entre 11,0 e 14,5g, após eliminação dos pesos extremos e dos ovos com gema dupla e com problemas de casca. A classificação dos ovos poderia ser uma prática indicada para codornas de corte se isso também refletisse em uniformidade dos lotes durante todo o período de criação. Os primeiros trabalhos visando estudar o efeito do peso do ovo sobre o desempenho de codornas de corte foram desenvolvidos por Corrêa et al. (2008ab), os quais observaram que codornas oriundas de ovos mais pesados apresentaram maior desempenho produtivo.

Assim, o objetivo deste trabalho foi avaliar o efeito da interação peso do ovo versus idade da matriz sobre o desempenho de codornas de corte do grupo genético EV1, nos $21^{\circ}$ e $42^{\circ}$ dias de idade.

\section{MATERIAL E MÉTODOS}

Foram utilizadas 840 matrizes de codornas de corte (Coturnix coturnix coturnix), linhagem EV1, nas classes de idades de 70, 205 e 280 dias. De cada classe foram incubados 600 ovos, separados em três categorias de peso: categoria 1 - ovos com 11,0-12,9g; categoria 2 - ovos com 13,0-14,9g e categoria 3 - ovos com 15,0-16,9g.

Após pesagem e classificação, os ovos, identificados com etiqueta adesiva numerada, foram acomodados em bandejas e incubados em temperatura e umidade controladas de $37,5^{\circ} \mathrm{C}$ e $60 \%$, respectivamente. No $15^{\circ}$ dia, foram colocados individualmente em saquinhos de filó - para total controle do indivíduo e do ovo - e transferidos para as bandejas de nascedouros, onde ficaram até o nascimento, no $18^{\circ}$ dia, em temperatura e umidade controladas de $37,2^{\circ} \mathrm{C}$ e $70 \%$. Após eclosão, para cada idade da matriz foram utilizadas 225 codornas de um dia, de 
ambos os sexos, provenientes das três categorias de peso, sendo 75 codornas de cada categoria. $\mathrm{O}$ delineamento experimental foi o inteiramente ao acaso, e os tratamentos consistiram da combinação de três classes de idades das matrizes e três categorias de peso de ovo, com cinco repetições de 15 codornas. As codornas, ao nascer, foram alojadas em baterias metálicas equipadas com bebedouro tipo copo e comedouro tipo calha. O programa de luz adotado foi de 23 horas diárias. A dieta, única para todos os tratamentos, continha $28 \%$ de proteína bruta e $2900 \mathrm{kcal}$ de energia metabolizável e foi formulada com base na composição dos ingredientes apresentada por Rostagno et al. (2000). O desempenho foi avaliado pelo ganho de peso (g), peso corporal (g) no $21^{\circ}$ e $42^{\circ}$ dias de idade, consumo da dieta (g/ave) e conversão alimentar (g de dieta/g de peso) do nascimento ao $21^{\circ}$ dia e do nascimento ao $42^{\circ}$ dia de idade. Os resultados foram submetidos à análise de variância, e as médias comparadas pelo teste SNK a 5\% de probabilidade. As análises dos dados foram realizadas por meio do programa SAEG (Sistema...2004).

\section{RESULTADOS E DISCUSSÃO}

Não houve interação significativa de classe de idade da matriz versus categoria de peso do ovo para peso corporal (PC), ganho de peso (GP), consumo da dieta (CD), conversão alimentar (CA) e viabilidade de codornas de corte no período do nascimento ao $21^{\circ}$ dia de idade, Tab. $1,2,3$, 4 e 5 , respectivamente.

Tabela 1. Médias do peso corporal (g) de codornas do grupo genético EV1 provenientes de matrizes de corte de três classes de idades e três categorias de peso dos ovos, do nascimento ao $21^{\circ}$ dia de idade

\begin{tabular}{ccccc}
\hline $\begin{array}{c}\text { Categoria de peso } \\
\text { do ovo }(\mathrm{g})\end{array}$ & \multicolumn{3}{c}{ Classe de idade da matriz (dias) } & \multirow{2}{*}{ Média } \\
\cline { 2 - 4 } & 70 & 205 & 280 & $151,3 \mathrm{c}$ \\
$11-12,9$ & 148,2 & 153,6 & 152,1 & $158,5 \mathrm{~b}$ \\
$13-14,9$ & 150,8 & 162,2 & 162,4 & $162,1 \mathrm{a}$ \\
\hline Média & 157,1 & 162,5 & 166,6 & \\
\hline
\end{tabular}

Médias seguidas de letras distintas maiúsculas na linha e minúsculas na coluna diferem entre si pelo teste SNK, a 5\% de probabilidade. $\mathrm{CV}=3,0 \%$.

Tabela 2. Médias do ganho de peso (g) de codornas do grupo genético EV1 provenientes de matrizes de corte de três classes de idade e três categorias de peso dos ovos, do nascimento ao $21^{\circ}$ dia de idade

\begin{tabular}{ccccc}
\hline Categoria de peso & \multicolumn{3}{c}{ Classe de idade da matriz (dias) } & \multirow{2}{*}{ Média } \\
\cline { 2 - 4 } do ovo $(\mathrm{g})$ & 70 & 205 & 280 & $143,0 \mathrm{~b}$ \\
\hline $11-12,9$ & 139,8 & 145,4 & 143,8 & $149,1 \mathrm{a}$ \\
$13-14,9$ & 141,2 & 152,8 & 153,2 & $151,5 \mathrm{a}$ \\
\hline $15-16,9$ & 146,4 & 151,8 & 156,2 & \\
\hline Média & $142,5 \mathrm{~B}$ & $150,0 \mathrm{~A}$ & $151,1 \mathrm{~A}$ & \\
\hline
\end{tabular}

Médias seguidas de letras distintas maiúsculas na linha e minúsculas na coluna diferem entre si pelo teste SNK, a 5\% de probabilidade. $\mathrm{CV}=3,2 \%$.

Tabela 3. Médias de consumo da dieta (g) de codornas do grupo genético EV1 provenientes de matrizes de corte de três classes de idade e três categorias de peso dos ovos, do nascimento ao $21^{\circ}$ dia de idade

\begin{tabular}{ccccc}
\hline Categoria de peso do & \multicolumn{3}{c}{ Classe de idade da matriz (dias) } & \multirow{2}{*}{ Média } \\
\cline { 2 - 4 } ovo (g) & 70 & 205 & 280 & \\
\hline $11-12,9$ & 276,8 & 280,7 & 295,6 & $28 \mathrm{c}$ \\
$13-14,9$ & 287,4 & 298,3 & 310,0 & $298,6 \mathrm{~b}$ \\
$15-16,9$ & 297,9 & 299,9 & 325,0 & $307,6 \mathrm{a}$ \\
\hline Média & $287,4 \mathrm{~B}$ & $293,0 \mathrm{~B}$ & $310,2 \mathrm{~A}$ & \\
\hline
\end{tabular}

Médias seguidas de letras distintas maiúsculas na linha e minúsculas na coluna diferem entre si pelo teste SNK, a 5\% de probabilidade. $\mathrm{CV}=4,0 \%$. 


\section{Corrêa et al.}

Para PC, GP e CD, o efeito da classe de idade da matriz e da categoria do peso do ovo foi significativo, Tab. 1, 2 e 3. Dentro da categoria de peso do ovo, o PC e o CD das codornas de corte no $21^{\circ}$ dia de idade aumentaram à medida que a categoria de peso dos ovos foi mais pesada, ou seja, codornas provenientes de ovos com 1516,9g apresentaram os maiores PC e CD, seguidas das codornas provenientes de ovos com 13-14,9g e com 11-12,9g. Estes resultados são justificados, pois o maior PC observado (Tab. 1) foi atribuído ao maior peso corporal das codornas ao nascer, oriundas de ovos mais pesados, o que levou ao maior consumo da dieta (Tab. 3), em consequência da maior exigência nutricional.

Para a variável GP (Tab. 2), dentro da categoria de peso do ovo, os melhores resultados ocorreram com as codornas oriundas dos ovos com pesos de 13-14,9g e 15-16,9g, os quais não diferiram entre si. Esses maiores GP também estão relacionados ao fato de as codornas mais pesadas consumirem mais ração. Corrêa et al. (2008a) também encontraram maiores peso corporal, ganho de peso e consumo de dieta ao $21^{\circ}$ dia de idade, em codornas de corte EV2, provenientes de ovos mais pesados.

Estes resultados podem ser explicados pelo fato de ovos maiores apresentarem maiores peso de gema e concentração de proteínas e fosfolipídios ao final do período de incubação, quando ocorre a transferência de nutrientes do saco vitelino para o embrião, e resultam em pintos mais pesados ao nascer, e seguido de melhor desenvolvimento deles (Noble et al., 1986; Ding e Lilburn, 1996). Resultados semelhantes foram encontrados por Dalanezi et al. (2005), os quais observaram maior consumo da dieta por frangos na fase inicial, oriundos de matrizes mais velhas. Esses autores esclareceram que as exigências líquidas de energia e proteína aumentaram à medida que aumentou o peso corporal da ave, levando ao maior consumo para atender à sua maior capacidade física de ingestão.

Dentro da classe de idade da matriz, os maiores PC e GP (Tab. 1 e 2) no $21^{\circ}$ dia de idade foram observados nas codornas oriundas de matrizes das classes de 205 e 280 dias de idade, os quais não diferiram entre si. Pinchasov (1991) observou que pintos de aves de corte, oriundos de matrizes mais velhas, tenderam a ser mais pesados que os de matrizes mais novas, no $18^{\circ}$ dia de idade.

Para o CD (Tab. 3), na classe de 280 dias, houve maior consumo do que nas classes de 70 e 205 dias, as quais não diferiram entre si. Este resultado está relacionado ao fato de as codornas oriundas de matrizes mais velhas (205 e 280 dias de idade) apresentarem maior peso corporal no $21^{0}$ dia e, consequentemente, maior consumo de dieta, em decorrência da maior exigência de mantença.

Houve efeito significativo da classe de idade da matriz sobre a conversão alimentar (Tab. 4), com melhor conversão alimentar apresentada pelas codornas da classe de 205 dias de idade.

Tabela 4. Médias de conversão alimentar (g/g) de codornas do grupo genético EV1 provenientes de matrizes de corte de três classes de idade e três categorias de peso dos ovos, do nascimento ao $21^{\circ}$ dia de idade

\begin{tabular}{ccccc}
\hline Categoria de peso do & \multicolumn{3}{c}{ Classe de idade da matriz (dias) } & \multirow{2}{*}{ Média } \\
\cline { 2 - 4 } ovo $(\mathrm{g})$ & 70 & 205 & 280 & $1,99 \mathrm{a}$ \\
$11-12,9$ & 1,98 & 1,93 & 2,06 & $2,00 \mathrm{a}$ \\
$13-14,9$ & 2,03 & 1,95 & 2,02 & $2,03 \mathrm{a}$ \\
\hline $15-16,9$ & 2,03 & 1,98 & 2,08 & \\
\hline Média & $2,02 \mathrm{~B}$ & $1,95 \mathrm{~A}$ & $2,05 \mathrm{~B}$ & \\
\hline
\end{tabular}

Médias seguidas de letras distintas maiúsculas na linha e minúsculas na coluna diferem entre si pelo teste SNK, a 5\% de probabilidade. $\mathrm{CV}=2,9 \%$.

Houve efeito significativo da classe de idade da matriz e categoria de peso do ovo sobre a viabilidade (Tab. 5). Considerando-se a viabilidade em função da categoria de peso do ovo, observou-se que os valores de viabilidade mais altos são para codornas oriundas de ovos com 15-16,9g e valores de viabilidades mais baixos são para codornas de ovos com 11-12,9g. Codornas oriundas de ovos com 13-14,9g apresentaram viabilidade intermediária, e este 
valor não diferiu $(\mathrm{P}>0,05)$ dos valores das demais categorias de peso dos ovos. Estes resultados sugerem que codornas mais pesadas ao nascimento apresentam maior viabilidade em virtude da maior resistência inicial, e constituem um indicativo de que as codornas provenientes de ovos mais leves necessitam de maiores cuidados, principalmente na primeira semana de alojamento, em que a taxa de mortalidade é alta. Corrêa et al. (2008a) trabalharam com matrizes de codornas de corte EV2 e não observaram diferença na viabilidade ao final do período do $21^{\circ}$ de idade. Da mesma forma, Lara et al. (2005) não observaram efeito do peso do pinto ao nascimento sobre a viabilidade no $21^{\circ}$ dia de idade em frangos de corte.

$\mathrm{Na}$ avaliação do desempenho do nascimento ao $42^{\circ}$ dia de idade, não houve efeito significativo da interação classes de idades da matriz versus categorias de peso do ovo sobre o PC, GP, CD, CA e viabilidade, Tab. 6, 7, 8, 9 e 10, respectivamente.

Tabela 5. Médias de viabilidade (\%) do grupo genético EV1 provenientes de matrizes de corte de três classes de idade e três categorias de peso dos ovos, do nascimento ao $21^{\circ}$ dia de idade

\begin{tabular}{ccccc}
\hline Categoria de peso & \multicolumn{3}{c}{ Classe de idade da matriz (dias) } & \multirow{2}{*}{ Média } \\
\cline { 2 - 4 } do ovo $(\mathrm{g})$ & 70 & 205 & 280 & $88,9 \mathrm{~b}$ \\
$11-12,9$ & 84,0 & 94,7 & 88,0 & $94,2 \mathrm{ab}$ \\
$13-14,9$ & 97,3 & 88,0 & 97,3 & $96,0 \mathrm{a}$ \\
\hline $15-16,9$ & 94,7 & 97,3 & 96,0 &
\end{tabular}

Médias seguidas de letras distintas maiúsculas na linha e minúsculas na coluna diferem entre si pelo teste SNK, a 5\% de probabilidade. $\mathrm{CV}=8,4 \%$.

Tabela 6. Médias do peso corporal (g) de codornas do grupo genético EV1 provenientes de matrizes de corte de três classes de idade e três categorias de peso dos ovos, do nascimento ao $42^{\circ}$ dia de idade

\begin{tabular}{ccccc}
\hline Categoria de peso do & \multicolumn{3}{c}{ Classe de idade da matriz (dias) } & \multirow{2}{*}{ Média } \\
\cline { 2 - 4 } ovo $(\mathrm{g})$ & 70 & 205 & 280 & \\
\hline $11-12,9$ & 271,2 & 289,3 & 282,3 & $280,9 \mathrm{~b}$ \\
$13-14,9$ & 270,9 & 288,5 & 293,7 & $284,4 \mathrm{~b}$ \\
$15-16,9$ & 284,5 & 296,3 & 300,9 & $293,9 \mathrm{a}$ \\
\hline Média & $275,5 \mathrm{~B}$ & $291,4 \mathrm{~A}$ & $292,3 \mathrm{~A}$ & \\
\hline
\end{tabular}

Médias seguidas de letras distintas maiúsculas na linha e minúsculas na coluna diferem entre si pelo teste SNK a 5\% de probabilidade. $\mathrm{CV}=3,6 \%$.

Tabela 7. Médias de ganho de peso (g) de codornas do grupo genético EV1 provenientes de matrizes de corte de três classes de idade e três categorias de peso dos ovos, do nascimento ao $42^{\circ}$ dia de idade

\begin{tabular}{ccccc}
\hline Categoria de peso & \multicolumn{3}{c}{ Classe de idade da matriz (dias) } & \multirow{2}{*}{ Média } \\
\cline { 2 - 4 } do ovo $(\mathrm{g})$ & 70 & 205 & 280 & $272,6 \mathrm{~b}$ \\
\hline $11-12,9$ & 262,8 & 281,1 & 274,0 & $275,0 \mathrm{~b}$ \\
$13-14,9$ & 261,3 & 279,2 & 284,5 & $283,3 \mathrm{a}$ \\
\hline $15-16,9$ & 273,8 & 285,6 & 290,5 & \\
\hline Média & $266,0 \mathrm{~B}$ & $281,9 \mathrm{~A}$ & $283,0 \mathrm{~A}$ & \\
\hline
\end{tabular}

Médias seguidas de letras distintas maiúsculas na linha e minúsculas na coluna diferem entre si pelo teste SNK a 5\% de probabilidade. $\mathrm{CV}=3,7 \%$.

Para PC, GP e CD, o efeito da classe de idade da matriz e da categoria do peso do ovo foi significativo (Tab. 6, 7 e 8). O PC e o GP no $42^{\circ}$ dia apresentaram o mesmo comportamento, ou seja, dentro da categoria de peso do ovo, codornas oriundas de ovos com 15-16,9g apresentaram maiores PC e GP seguidas das codornas provenientes de ovos com 11-12,9 e 13-14,9g (Tab. 6), que não diferiram entre si. Isso pode ser atribuído ao fato de que ovos mais pesados deram origem a codornas mais pesadas ao nascimento, e, consequentemente, estas apresentaram maiores pesos corporais e maiores ganhos de pesos após o nascimento. Corrêa et al. (2008b) também observaram maior peso corporal para codornas de corte oriundas de ovos mais 


\section{Corrêa et al.}

pesados, e Lara et al. (2005) observaram, em frangos de corte, que os originários de pintos mais pesados ao nascimento eram mais pesados e consumiram mais ração no $43^{\circ}$ dia de idade. Dentro da classe de idade da matriz, codornas oriundas de matrizes das classes de 205 e 280 dias foram mais pesadas do que as oriundas da classe de 70 dias de idade.

Houve maior consumo da dieta (Tab. 8) para codornas oriundas de ovos com 15-16,9g e menor para as oriundas de ovos com 11-12,9g. As codornas provenientes de ovos com 13-14,9g apresentaram CD intermediário, não diferindo das demais categorias de peso do ovo. Estes resultados de $\mathrm{CD}$ ocorreu em função de as codornas apresentarem maior PC e, portanto, necessitarem de maior quantidade de alimento para atender às suas exigências nutricionais de mantença e crescimento. Observou-se maior CD para codornas oriundas de matrizes das classes de 205 e 280 dias de idade, valores que não diferiram entre si $(\mathrm{P}>0,05)$. Isto está relacionado ao fato de as codornas mais velhas produzirem tanto ovos quanto codornas ao nascimento mais pesadas e, consequentemente, maior peso corporal durante todo o período de crescimento.

Tabela 8. Médias de consumo da dieta (g) de codornas do grupo genético EV1 provenientes de matrizes de corte de três classes de idade e três categorias de peso dos ovos, do nascimento ao $42^{\circ}$ dia de idade

\begin{tabular}{ccccc} 
Categoria de peso do & \multicolumn{3}{c}{ Classe de idade da matriz (dias) } & \multirow{2}{*}{ Média } \\
\cline { 2 - 4 } ovo $(\mathrm{g})$ & 70 & 205 & 280 & \\
\hline $11-12,9$ & 874,6 & 925,2 & 903,4 & $901,1 \mathrm{~b}$ \\
$13-14,9$ & 878,3 & 956,0 & 936,8 & $923,7 \mathrm{ab}$ \\
$15-16,9$ & 927,7 & 948,3 & 966,5 & $947,5 \mathrm{a}$ \\
\hline Média & $893,6 \mathrm{~B}$ & $943,2 \mathrm{~A}$ & $935,6 \mathrm{~A}$ & \\
\hline
\end{tabular}

Médias seguidas de letras distintas maiúsculas na linha e minúsculas na coluna diferem entre si pelo teste SNK a 5\% de probabilidade. $\mathrm{CV}=3,7 \%$.

Não houve diferença significativa para conversão alimentar (Tab. 9) entre as classes de idade das matrizes e categoria de peso do ovo, à semelhança dos resultados observados em codornas de corte por Lara et al. (2005) e por Corrêa et al. (2008b), em frangos de corte.

Tabela 9. Médias de conversão alimentar (g/g) de codornas do grupo genético EV1 provenientes de matrizes de corte de três classes de idade e três categorias de peso dos ovos, do nascimento ao $42^{\circ}$ dia de idade

\begin{tabular}{ccccc}
\hline $\begin{array}{c}\text { Categoria de peso } \\
\text { do ovo }(\mathrm{g})\end{array}$ & 70 & 205 & Classe de idade da matriz (dias) & \multirow{2}{*}{ Média } \\
\cline { 2 - 4 } & 3,33 & 3,29 & 280 & 3,31 \\
$11-12,9$ & 3,36 & 3,43 & 3,30 & 3,36 \\
$13-14,9$ & 3,39 & 3,32 & 3,33 & 3,35 \\
\hline Média & 3,36 & 3,35 & 3,31 & \\
\hline
\end{tabular}

Melhores resultados de viabilidade ao $42^{\circ}$ dia de idade (Tab. 10) foram observados para codornas provenientes de ovos mais pesados das categorias de 13-14,9 e 15-16,9g. Estes resultados estão de acordo com os encontrados por Leandro et al. (2006), ao constatarem que pintos de corte com maior peso inicial pesavam mais ao final, ganharam mais peso, e a viabilidade foi maior ao $40^{\circ}$ dia de idade. Isso está relacionado ao maior peso das codornas ao nascimento (Tab. 11). Assim, ovos muito leves originariam codornas de um dia mais leves, que apresentariam menor viabilidade ao final do período de criação, o que refletiria em menor rentabilidade. Codornas oriundas de diferentes classes de idade da matriz não diferiram entre si quanto à viabilidade.

Em relação ao peso da codorna ao nascer (Tab. 11), houve interação significativa de categoria de peso do ovo versus classe de idade da matriz. Dentro de classes de idade da matriz, para cada categoria de peso do ovo, observou-se que codornas oriundas de matrizes mais novas (70 dias de idade) apresentaram maior peso ao nascimento $\quad(\mathrm{P}<0,05)$, porém com efeito 
diferenciado para cada categoria de peso de ovo. Isso pode ser explicado pela transformação que ocorre na casca, cutícula e membranas do ovo, com o avançar da idade da matriz, que, neste caso, pode ter influenciado a perda de água durante o processo de incubação, gerando codornas mais leves ao nascimento, quando originadas de matrizes mais velhas, mesmo com ovos classificados na mesma categoria de peso, conforme relatado por Roque e Soares, (1994) e Santos et al. (2009). Já codornas provenientes de categorias de ovos mais pesados e de todas as classes de idade da matriz (Tab. 11) foram mais pesadas ao nascimento $(\mathrm{P}<0,05)$. Isso demonstra uma forte associação entre o peso do ovo à incubação e o peso do pinto, conforme observado por outros autores para frangos de corte (Pinchasov, 1991; Wilson, 1991).

Tabela 10. Médias de viabilidade (\%) do grupo genético EV1 provenientes de matrizes de corte de três classes de idade e três categorias de peso dos ovos, do nascimento ao $42^{\circ}$ dia de idade

\begin{tabular}{ccccc}
\hline Categoria de peso do & \multicolumn{3}{c}{ Classe de idade da matriz (dias) } & \multirow{2}{*}{ Média } \\
\cline { 2 - 4 } ovo $(\mathrm{g})$ & 70 & 205 & 280 & \\
\hline $11-12,9$ & 81,3 & 89,3 & 86,7 & $85,8 \mathrm{~b}$ \\
$13-14,9$ & 96,0 & 85,3 & 96,0 & $92,4 \mathrm{a}$ \\
$15-16,9$ & 93,3 & 93,3 & 94,7 & $93,8 \mathrm{a}$ \\
\hline Média & $90,2 \mathrm{~A}$ & $89,3 \mathrm{~A}$ & $92,4 \mathrm{~A}$ & \\
\hline
\end{tabular}

Médias seguidas de letras distintas maiúsculas na linha e minúsculas na coluna diferem entre si pelo teste SNK, a 5\% de probabilidade. $\mathrm{CV}=9,8 \%$.

Tabela 11. Médias de peso da codorna de um dia (g) do grupo genético EV1 provenientes de matrizes de corte de três classes de idades e três categorias de peso dos ovos

\begin{tabular}{ccccc}
\hline Categoria de peso & \multicolumn{3}{c}{ Classe de idade da matriz (dias) } & \multirow{2}{*}{ Média } \\
\cline { 2 - 4 } do ovo $(\mathrm{g})$ & 70 & 205 & 280 & 8,3 \\
$11-12,9$ & $8,4 \mathrm{Ac}$ & $8,2 \mathrm{Cc}$ & $8,3 \mathrm{Bc}$ & 9,4 \\
$13-14,9$ & $9,6 \mathrm{Ab}$ & $9,4 \mathrm{Bb}$ & $9,2 \mathrm{Cb}$ & $10,4 \mathrm{Ba}$ \\
$15-16,9$ & $10,7 \mathrm{Aa}$ & $10,7 \mathrm{Aa}$ & 9,3 & \\
\hline Média & 9,6 & 9,4 & 9,4
\end{tabular}

Médias seguidas de letras distintas maiúsculas na linha e minúsculas na coluna diferem entre si pelo teste SNK a 5\% de probabilidade. $\mathrm{CV}=0,44 \%$

\section{CONCLUSÕES}

Maior peso do ovo influi positivamente no peso corporal, ganho de peso e consumo da dieta de codornas de corte no $21^{\circ}$ e no $42^{\circ}$ dia de idade. Maior viabilidade é observada em codornas oriundas de ovos mais pesados ao nascimento e aos $21^{\circ}$ e $42^{\circ}$ dias de idade. As codornas oriundas de matrizes de classes de idade iniciadas aos 205 e 280 dias apresentaram melhor desempenho produtivo.

\section{AGRADECIMENTOS}

À FAPEMIG, pelo financiamento do projeto.

\section{REFERÊNCIAS BIBLIOGRÁFICAS}

CORRÊA, A.B.; SILVA, M.A.; CORRÊA, G.S.S. et al. Efeito do peso do ovo sobre o desempenho de codornas de corte avaliadas no $21^{\circ}$ dia de idade. In: CONGRESSO BRASILEIRO DE ZOOTECNIA, 18., 2008, João Pessoa. Anais... João Pessoa: ABZ, 2008a. p.1-3. (CD-ROM).

CORRÊA, A.B.; SILVA, M.A.; CORRÊA, G.S.S. et al. Influência do peso do ovo nas características de desempenho de codornas de corte no $42^{\circ}$ dia de idade. In: CONGRESSO BRASILEIRO DE ZOOTECNIA, 18., 2008, João Pessoa. Anais... João Pessoa: ABZ, 2008b. p.1-3. (CD-ROM). 


\section{Corrêa et al.}

DALANEZI, J.A.; MENDES, A.A.; GARCIA, E.A. et al. Efeito da idade da matriz sobre o desempenho e rendimento de carcaça de frangos de corte. Arq. Bras. Med. Vet. Zootec., v.57, p.250-260, 2005.

DING, S.T.; LILBURN, M.S. Characterization of changes in yolk sac and liver lipids during embryonic and early post hatch development of turkey poults. Poult. Sci., v.75, p.478-483, 1996.

LARA, L.J.C.; BAIÃO, N.C.; CANÇADO, S.V. et al. Influência do peso inicial sobre o desempenho e o rendimento de carcaça e cortes de frangos de corte. Arq. Bras. Med. Vet. Zootec., v.57, p.799-804, 2005.

LEANDRO, L.S.M.; CUNHA, W.C.P.; STRINGHINI, J.H. et al. Influência do peso inicial de pintos de corte sobre o desempenho e o rendimento de carcaça de frangos e a viabilidade econômica da produção. Rev. Bras. Zootec., v.35, p.2314-2321, 2006.

MAYORKA, A.; LUQUETTI, B.C. ALMEIDA, J.G. et al. Idade da matriz e qualidade do pintinho. In: MACARI, M.; GONZALES, K. (Eds). Manejo da incubação.Campinas: Facta, 2003. P. 361-377.

NOBLE, R.C.; LONSDALE, F.; CONNOR, K. et al. Changes in the lipid metabolism of the chick embryo with parental age. Poult. Sci., v.65, p.409-416, 1986.

PINCHASOV, Y. Relationship between the weight of hatching eggs and subsequent early performance of broiler chicks. Br. Poult. Sci., v.32, p.109-115, 1991.
REIS, L.H.; GAMA, L.T.; CHAVEIRO SOARES, M. Effects of short storage conditions and broiler breeder age on hatchability, hatching time, and chick weights. Poult. Sci., v.76, p.1459-1466, 1997

ROCHA, J.S.R.; LARA, L.J.C.; BAIÃO, N.C. et al. Efeito da classificação dos ovos sobre o rendimento de incubação e os pesos do pinto e do saco vitelino. Arq. Bras. de Med. Vet. Zootec., v.60, p.979-986, 2008.

ROQUE, L.; SOARES, M.C. Effects of eggshell quality and broiler breeder age on hatchability. Poult. Sci., v.73, p.1838-1845, 1994.

ROSTAGNO, H.S.; ALBINO, L.F.T.; DONZELE, J.L. et al. Tabelas brasileiras para aves e suínos: composição de alimentos e exigências nutricionais de aves e suínos. Viçosa: UFV, 2000. 141p.

SANTOS, J.E.C.; GOMES, F.S.; BORGES, G.L.F.N. et al. Efeito da linhagem e da idade das matrizes na perda de peso dos ovos e no peso embrionário durante a incubação artificial. Biosci. J., v.25, p.163-169, 2009.

SISTEMA de análises estatísticas - SAEG. Versão 9.0. Viçosa: UFV, 2004.

VIEIRA, S.L.; MORAN Jr., E.T. Effects of egg of origin and chick post-hatch nutrition on broiler live performance and meat yields. World's Poult. Sci. J., v.55, p.125-142, 1999.

WILSON, H.R. Interrelationships of egg size, chick size, posthatching growth and hatchability. World's Poult.Sci. J., v.47, p.5-20, 1991. 